\title{
Most Important Chronic Complications of Arteriovenous Fistulas for Hemodialysis
}

\author{
Radojica Stolic \\ Faculty of Medicine, University of Pristina, Kosovska Mitrovica, Serbia
}

\section{Key Words}

Arteriovenous fistula $\cdot$ Hemodialysis $\cdot$ Complications

\begin{abstract}
The aim of this review was to highlight the most important complications of arteriovenous fistulas (AVFs) for hemodialysis (HD). The quality of vascular access for HD should be suitable for repeated puncture and allow a high blood flow rate for high-efficiency dialysis with minimal complications. The dialysis staff must be well versed in manipulation of the AVF, and there should be a minimal need for corrective interventions. Construction of an AVF creates conditions for increasing the flow of blood through the venous system. Fulfillment of these conditions reduces the risk of turbulence and endothelium injury, which, in turn, minimizes the potential for stenosis. An AVF is closest to the ideal model of vascular access. The most important complications of fistulae for HD are lymphedema, infection, aneurysm, stenosis, congestive heart failure, steal syndrome, ischemic neuropathy and thrombosis. In HD patients, the most common cause of vascular access failure is neointimal hyperplasia. It is important to gain information about early clinical symptoms of AVF dysfunction in order to prevent and adequately treat potential complications.

Copyright $\odot 2012$ S. Karger AG, Basel
\end{abstract}

\begin{tabular}{ll}
\hline KARGER & $\begin{array}{l}\text { (c) 2012 S. Karger AG, Basel } \\
1011-7571 / 13 / 0223-0220 \$ 38.00 / 0\end{array}$ \\
$\begin{array}{l}\text { E-Mail karger@karger.com } \\
\text { www.karger.com/mpp }\end{array}$ & $\begin{array}{l}\text { This is an Open Access article licensed under the terms } \\
\text { of the Creative Commons Attribution-NonCommercial- } \\
\text { NoDerivs 3.0 License (www.karger.com/OA-license), appli- } \\
\text { cable to the online version of the article only. Distribution } \\
\text { for non-commercial purposes only. }\end{array}$
\end{tabular}

\section{Introduction}

A shift in the treatment of hemodialysis (HD) patients occurred when James E. Cimino noted that arteriovenous fistulas (AVFs) caused by trauma in Korean war veterans did not have significant effects on their health. This led to his proposal that AVFs would be an ideal solution for easy access to the circulation in patients on HD [1-3].

Since the Centers for Medicare \& Medicaid Services recognized the clinical and economic advantages of AVFs, the National Kidney Foundation's Kidney Disease Outcomes Quality Initiative (KDOQI) and the Fistula First Initiative have made increasing the prevalence of AVFs a priority [4]. Several studies indicate that about $30 \%$ of hospitalizations are caused by the construction and complications of vascular access [5]. The annual cost of maintaining vascular access is around USD 600 for AVFs up to as much as USD 5,000 for arteriovenous grafts (AVGs). High costs of implementation and maintenance of vascular access may arise from occasional diagnostic procedures, which further increase the annual costs of USD 1,020 for AVFs and USD 1,610 for AVGs, which represent $14-20 \%$ of total health care costs for dialysis patients [4-8]. Nevertheless, timely formation of AVFs reduced the mortality rate by 1.72 times [6].

The quality of vascular access for HD should be suitable for repeated puncture and allow a fast blood flow rate

Prof. Radojica Stolic Faculty of Medicine Anri Dinan bb

RS-38220 Kosovska Mitrovica (Serbia)

E-Mail radojica.stolic@med.pr.ac.rs 
for high-efficiency dialysis with minimal complications. Therefore, a long-term functioning AVF needs a welltrained surgeon to create it and enough time allowed for maturation. The dialysis staff must be well versed in cannulation of the AVF, and there should be a minimal need for corrective interventions. Yet it must be recognized that, under the present circumstances, an ideal approach really does not exist $[9,10]$.

European good clinical practice guidelines for vascular access suggest preservation of the venous system and that all patients who are committed to HD treatment already have an established vascular access at the beginning of dialysis. Early referral of patients to a nephrologist is not only necessary to preserve the blood vessels, but also has psychological significance in the preparation for dialysis treatment, allows identification of possible options for dialysis modalities and enables correction of the anemic syndrome, hypertension and metabolic disorders. Patience, trust and compromise between doctors, patients and the dialysis staff should lead to successful placement of vascular access [11-15]. Most guidelines recommend assessment of patients for access creation at the CKD 4 stage. A fistula should be placed at least 6 months before the anticipated start of HD treatments [16].

\section{Is There a Contraindication to the Creation of Vascular Access?}

When AVFs were introduced into routine clinical practice, only people younger than 40 years with chronic renal failure as a consequence of diabetes mellitus were considered unsuitable for any form of therapy. However, nowadays, in addition to the elderly and diabetics, patients suffering from congestive heart failure are considered to be risk groups for the creation of vascular access. Absolute contraindications to this are amputation of extremities and advanced peripheral artery disease with consecutive necrosis. However, the final decision on the quality of the vasculature is made after a noninvasive color Doppler ultrasound examination [3].

\section{Complications during and Immediately after Surgical Intervention}

\section{Surgical Issues}

The choice of operative technique for anastomosis has its own characteristics and it is a very important procedure in order to avoid certain surgical complications.
End-to-end anastomosis requires a formidable surgical technique, especially when there is a discrepancy between the lumen of the arteries and veins. This can lead to ischemia of the distal extremities, especially in the elderly and patients with diabetes mellitus. Side-to-side anastomosis is technically easier and can be done if the blood vessels are close to each other. It must be noted that this type of anastomosis may lead to development of venous hypertension. Currently, the most acceptable option is end-to-side anastomosis $[3,8,11]$.

AVF construction creates conditions for increasing the flow of blood through the venous system. Before surgery, systemic venous pressure is about $20 \mathrm{~mm} \mathrm{Hg}$, but immediately afterwards it increases to between 60 and $120 \mathrm{~mm} \mathrm{Hg}$. Therefore, when making the anastomosis, it is important to avoid the possibility of creating obstacles to blood flow. One should not make an acute angle, longitudinally rotate the veins, or change their anatomical position. Fulfillment of these conditions reduces the risk of turbulence and endothelium injury, which, in turn, minimizes the potential for stenosis. Surgical complications can be defined as complications during the intervention due to discrepancies between the lumen diameters of the arteries and veins, narrowing of the anastomosis, damaged intima media, or interposition of adventitia and the remaining collateral [12].

It is noteworthy that the routine application of antibiotics is not acceptable. It is also important to note that there is no consensus on indications for the formulaic application of anticoagulant treatment because surgical errors cannot be corrected by pharmacotherapy [12]. Immediately after surgery, hemorrhage, low venous flow or hematoma may occur. At a later stage, there may be complications, such as infections, the development of an aneurysm and/or false aneurysm, fistula vein stenosis, congestive heart failure, steal syndrome, ischemic neuropathy and thrombosis (table 1).

Creation and maintenance of vascular access cannot exclude the occurrence of lymphedema.

\section{Infections}

Infection accounts for $20 \%$ of all AVF complications [17], which is ten times lower than the rate of infection of AVGs $[18,19]$. Most AVF infections involve perivascular cellulitis, which manifests as localized erythema and edema and is usually easily treated. Much more serious is an infection associated with anatomical abnormalities, such as aneurysms, hematomas or abscesses, which require surgical excision and drainage [17]. 
Table 1. Clinical features and incidence of the most common complications of AVFs

\begin{tabular}{|c|c|c|}
\hline $\begin{array}{l}\text { Complications of AVFs } \\
\text { associated with chronic use }\end{array}$ & Clinical features & $\begin{array}{l}\text { Incidence } \\
\%\end{array}$ \\
\hline Thrombosis & $\begin{array}{l}\text { Severe pain at the site of thrombosis, palpation of thrombus at the AVF site, tremors and } \\
\text { absence of feeling }\end{array}$ & $17-25$ \\
\hline Stenosis & $\begin{array}{l}\text { Difficulties in cannulation, painful arm edema, prolonged bleeding time after cannulation } \\
\text { or after removal of the dialysis needles }\end{array}$ & $14-42$ \\
\hline Ischemic neuropathy & $\begin{array}{l}\text { Severe pain distal to the anastomosis, sensory loss, weakness of the hand and fingers, and } \\
\text { eventually paralysis of the muscles innervated by the radial, ulnar and median nerves }\end{array}$ & $1-10$ \\
\hline Steal syndrome & $\begin{array}{l}\text { Pale/blue and/or cold hand without pain/or pain during exercise and/or hemodialysis, } \\
\text { ischemic pain at rest, ulceration, necrosis and gangrene }\end{array}$ & $2-8$ \\
\hline
\end{tabular}

Different clinical and microbiological characteristics may indicate AVF infection. Clinical suspicion arises after visible signs of inflammation at the vascular access puncture site (calor, dolor and rubor) with or without systemic manifestations. Localized infections occurring after AVF puncture are treated with appropriate antibiotics based on the results of swab and blood cultures. AVF infections are very rare and in most cases respond well to antibiotic treatment, lasting 4-6 weeks. A ligature of the AVF is required only when it becomes a source of recurrent septic pulmonary embolism $[17,19]$.

\section{Aneurysmal Enlargement of Blood Vessel Walls}

An aneurysm is a pathological enlargement of the blood vessel wall resulting from repetitive puncture [14]. False aneurysms are hematomas located outside the vessel wall, formed due to a leaking hole in the artery, most often due to iatrogenic trauma - primarily repeated needle punctures [20]. Color Doppler ultrasound can differentiate false-aneurysm expansion from a hematoma, the presence of a thrombotic mass, which enables a decision to be made on possible surgical correction. Surgical intervention is recommended when there is a risk of perforation and ulceration if there are elements of bleeding or if there is a limited place for puncture because of the size of the aneurysm [21].

\section{Stenosis}

Thrombosis is a crucial cause of loss of function of an AVF. It usually occurs near a stenosis in the area of anas- tomosis or fistula vein. Uremic factors such as homocysteine or endogenous inhibitors of NO synthase (asymmetric dimethylarginine) could be directly toxic to the vascular endothelium [22]. In patients with end-stage renal disease, in addition to the impaired vasodilatation of capacitance vessels due to endothelial dysfunction, reduced venous distensibility occurs [23]. Vein wall distensibility is controlled by collagen, elastin and smooth muscle. Wali et al. [24] demonstrated accumulation of collagen fibers in place of smooth muscle cells in preaccess cephalic veins, causing a decrease in the elasticity of the vein wall. This process reduces the functional properties of forearm blood vessels, and thus interferes with the proper maturation of the AVF. The risk of thrombosis increases with the degree of stenosis. KDOQI guidelines define significant stenosis of the vessel lumen as a reduction by more than $50 \%$. Clinical suspicion of stenosis is confirmed by the presence of several factors: reduced quality of dialysis, problems with puncture, such as prolonged bleeding after AVF puncture, pain in the area of the fistula or increased venous pressure. Recirculation is an important issue since it appears to be a significant cause of inadequate HD. The most common cause is the presence of high-grade venous stenosis, which obstruct venous outflow, leading to backflow into the arterial needle. Recirculation is diagnosed when dialyzed blood returning through the venous side reenters the dialyzer through the arterial needle rather than returning to the systemic circulation, and as a result, the efficiency of HD is reduced [14]. It must be pointed out 
that stenosis may be due to extraluminal compression by an abscess, hematoma or seroma. The peak systolic velocity in Doppler ultrasound is used to determine the existence of stenosis. Values greater than $400 \mathrm{~cm} / \mathrm{s}$ indicate the presence of stenosis; a monthly decline in flow by $20-25 \%$ is also considered significant for this type of complication. Angiography is a reliable technique for determining stenosis but is more expensive and technically demanding. Treatment involves balloon dilatation of the stenosis, stent implantation or surgical revision $[12,20]$. Percutaneous transluminal angioplasty (PTA) in the treatment of vascular access stenosis improves fistula function and prolongs fistula survival in patients with shorter lesions $(<1 \mathrm{~cm})$, but restenosis remains the major problem. Although percutaneous interventions are less invasive than surgical revision for preserving vascular access, long-lasting PTA outcomes have not been demonstrated to be useful. Concerted efforts of nephrologists, interventional radiologists and surgeons are key to maintaining and prolonging function of the vascular access [12, 25-27].

\section{Impact of AVFs in Heart Failure}

Some authors believe that cardiac decompensation in patients with AVFs occurs only in individuals with previously chronic heart disease. Preliminary data show a trend towards left ventricular hypertrophy $(\mathrm{LVH})$ in patients with an AVF [28] flow exceeding 2,000 ml, but there are no guidelines about possible interventions in the AVF to prevent the occurrence of heart failure [29]. Cardiovascular complications are the leading cause of death in patients on HD, and LVH is the most common cardiac change in patients with end-stage renal failure, which is observed in $74 \%$ of patients at the beginning of $\mathrm{HD}$ treatment, probably as a result of adaptation to the hemodynamic changes after shunt creation [30, 31]. Development and progression of LVH in HD patients is complex and often multifactorial; pathogenetic factors include volume overload, creation of an AVF, anemia and pressure overload. LVH is an adaptive response to increased cardiac workload that has short-term beneficial effects on cardiac function but long-term detrimental consequences [31, 32].

The mechanisms of hemodynamic compensation in HD patients are very complex and involve, among other things, reduced vascular resistance and arterial dilatation as a result of increased blood flow and the formation of collaterals. Although AVFs have a detrimental effect on cardiac function, the exact role of the vascular access is not sufficiently clear. It is assumed that the construction of an AVF increases cardiac output by $15 \%$ and end-diastolic ventricular pressure by $4 \%$ [30].

There are no significant studies that would indicate the incidence of LVH after AVF creation. Individual results in small cohorts of patients indicate that the rate of $\mathrm{LVH}$ is between 12.2 and $17 \%[33,34]$. In a situation when heart failure is not etiologically clear enough, stimulation of natriuretic peptide synthesis by the AVF increases intravascular volume, which may be a predictive parameter of mortality in these patients. Previous studies showed that plasma levels of B-type natriuretic peptide (as a marker of volume overload/left ventricle distension) increased in LVH after creation of an AVF [35] and in the short-term [36]. Unfortunately, there is no valid evidence that closing fistulas reduces cardiovascular risk because this would require a large number of respondents. Available data suggest that after ligation of the AVF, changes in the architectonics of the left ventricle do not provide the expected beneficial effect [30].

\section{Vascular Access-Induced Ischemia}

A developed AVF can cause reduced blood flow distal to the arteriovenous anastomosis, which leads to hypoxia, ischemia and necrosis. The risk of ischemia and the emergence of this syndrome, known in the literature as the steal syndrome, are especially high in diabetics and elderly people. Clinical signs include reduced movement of the wrist with a sense of coldness in the hand and a color change to pale yellow, or purple, pain at rest and during exercise and peripheral necrosis [37]. Low resistance in the system of fistula veins and retrograde flow in the area of the palmar arch jeopardize adequate perfusion of the hands. There is evidence that the steal syndrome in risk groups may occur in $75-90 \%$ of patients after creation of an AVF. This phenomenon remains clinically asymptomatic until the moment when compensatory mechanisms for perfusion by peripheral arteries are exhausted [38].

In most cases, an AVF does not compromise perfusion of the hand [39]. However, $1.6-8 \%$ of patients develop unilateral ischemia of the hand [40]. In general, for the occurrence of ischemia in the hand with a fistula, certain conditions are required: primarily, reduced blood flow through the arterial system due to arterial occlusive disease proximal or distal from the arteriovenous anastomosis. The steal syndrome may arise from excessive blood flow through a dilated blood vessel together with insufficient vascular adaptation and reduced collateral perfusion. This ischemia is often mild, but severe longterm hypoperfusion leads to tissue necrosis requiring 
amputation of fingers and/or forearm in $1 \%$ of patients [39]. Pathophysiological mechanisms of vascular accessinduced distal ischemia are complex and not well known. Symptoms of arterial blood diversion are more common in patients with diabetes mellitus and smokers [41, 42]. Vascular access-induced hand ischemia is a common clinical symptom, perhaps 1 in 500 cases, most likely due to the rich collateral vascular network and small muscle mass. Data in the literature suggest that symptomatic ischemia develops in $10-25 \%$ of patients with brachiocephalic and brachiobasilic vascular access, $4-6 \%$ at the level of the forearm and $1-2 \%$ at the radiocephalic level [43]. Due to the increasing age of patients on HD as well as a rising number of comorbidities, the incidence of hand ischemia is significantly increasing. It is assumed that in the future, the frequency of these ischemias will rise due to popularization of vascular access in the proximal region of the elbow, as well as the growing number of elderly people on HD [43]. Treatment of this condition is difficult and the risk of amputation of fingers and the forearm is great. Therefore, attention must be focused on prevention, which includes adequate preoperative assessment, use of Doppler ultrasound, and a precise surgical technique that involves arteriotomy no greater than $7 \mathrm{~mm}$ as well as being within the range of a $90-180^{\circ}$ angle of anastomosis. Failure to use these precise surgical techniques may lead to increased resistance and reduced blood flow [40, 43]. So far, there are five known therapeutic options for the treatment of distal arm ischemia caused by vascular access. One important operational technique is called distal revascularization interval ligation (DRIL), a procedure introduced in 1983 as a treatment option for distal ischemia caused by vascular access. The essence of this operation is stopping retrograde diastolic inflow into the fistula as the pathophysiologic principle of the steal syndrome [44]. However, the strategic application of a treatment depends on the severity of symptoms, comorbidities and the skill of the surgical team. In milder cases, we monitor the development of symptoms, and a radical approach is not required. Percutaneous transluminal angioplasty with possible stent implantation in the case of a stenotic lesion is carried out as a part of diagnostic arteriography and may be a therapeutic option for a third of cases $[40,45]$.

\section{Ischemic Polyneuropathy}

Ischemic neuropathy is most common in diabetic patients with severe forms of peripheral arterial disease, especially when the brachial artery is used for creation of vascular access. It is manifested by weak arms, in the im- mediate preoperative period, severe pain, and paresthesia. Neurological examination shows weakness in distal muscle groups in the area of sensory innervation by a defective median nerve [30]. The frequency of such complications varies between 1 and 10\%. The syndrome develops quickly (typically within hours) of AVF creation $[46,47]$.

\section{Thrombosis}

The main role of the endothelium in hemostasis is its antithrombotic function. A normal hemostatic reaction is initiated by damage to blood vessel walls, exposing the subendothelial structures to blood flow, resulting in the formation of a thrombus [48]. Fibrinogen and fibrin D dimer are independent risk factors for thrombosis of vascular access in patients on HD and are associated with intra- and extravascular activation of the coagulation system $[49,50]$.

Most studies paradoxically indicate disturbances of platelet adhesion, thus explaining the tendency to increased bleeding. Thus, a question arises about the circumstances leading to frequent coagulation at the vascular access. It is believed that HD platelets are activated by adhesion to the extracellular circulatory system and the turbulence in blood flow generated by the vascular access. Fibrinogen, which has an increased concentration in patients on chronic HD [49], activates platelets and increases further platelet deposition. Adherent platelets release platelet-derived growth factor to initiate intimal hyperplasia, thereby reducing blood flow. This creates conditions for the deposition of activated and inactivated platelets, which, despite a tendency to bleeding, favors thrombosis of the vascular access [50]. Significant studies indicate that clopidrogel reduced the frequency of early thrombosis of new AVFs, and did not increase bleeding events during a 6-week administration period. Maintenance of patency is necessary for fistula maturation, which means that prevention of early thrombosis would be associated with a higher rate of fistula maturation. A beneficial effect of clopidogrel on fistula patency but not on suitability is important to the evolving understanding of the pathophysiology of fistula maturation and failure, and suggests that early patency is necessary but not sufficient for fistula maturation. The discrepancy between the effects of clopidogrel on fistula patency and fistula suitability indicates that thrombosis may be a manifestation rather than a cause of maturation failure [51].

An important cause of complications in HD patients is an increased thrombotic tendency, causing many fatalities involving ischemic heart disease or stroke, but in 
$17-25 \%$ of cases the reason for hospitalization is AVF thrombosis $[52,53]$. The most common cause of vascular access thrombosis is venous neointimal proliferation. This causes vascular stenosis, leading to fistula thrombosis [53]. Neointimal hyperplasia is characterized by the proliferation of smooth muscle cells under the influence of basic fibroblast- and platelet-derived growth factors. The smooth muscle cell layer penetrates through the internal elastic lamina, migrates into the intima, and secretes matrix proliferous substances, such as collagen, elastin and proteoglycans. During migration of smooth muscle cells into the intima, they are transformed from a contractile into a secretory type that produces a basic substance causing intimal fibrosis [54]. Parallel clinical studies were carried out on the correlation of dysfunction of vascular access for HD and coronary artery stenosis because it is assumed that the vascular access for HD is an ideal model for determining the therapeutic protocol for vascular stenosis [55].

The vascular endothelial cell is a dynamic medium placed between the wall and lumen of vessels. Its core functions are maintenance of vascular tone and blood flow, prevention of vascular inflammation and proliferation of smooth muscle cells, as well as fibrinolytic, antiinflammatory, anticoagulant and antiplatelet functions [56].

However, the altered hemodynamic conditions resulting from arteriovenous anastomosis induce mechanisms of vascular remodeling, contributing to the emergence and development of endothelial dysfunction. This, together with increased oxidative stress, is an important promoter of inflammatory processes. Endothelial vasodilator activity (nitric oxide, prostacyclin and bradykinin) is significantly reduced, while the synthesis of powerful vasoconstrictors (endothelin, angiotensin II and free oxygen radicals) is increased. Restenosis is one of the important pathophysiological events in the endothelium of blood vessels; it may occur after percutaneous transluminal methods of angioplasty. Another important process that leads to renarrowing of blood vessels is neointimal hyperplasia with proliferation of smooth muscle cells and endothelial cells $[57,58]$.

The kinetics of the proliferation response, which was demonstrated in animal models, indicated an important role for certain glycoproteins ( $\mathrm{v} \beta 3$ integrins) as a stimulus for platelet-derived growth factor, proliferation of smooth muscle cells [59], pro-inflammatory agents (MCP-1, PAI-1, ET-1) [60], interleukin-1 [61] and early changes in venous wall contractility [62]. On the other hand, recent research in humans indicated that about
$90 \%$ is dominated by proliferation and neovascularization of the subendothelial layer, with macrophage infiltration of monocyto-intimal endothelial cells [63].

In the first 7 days after implantation of vein grafts in animals, there is degeneration and loss of cell wall storage with simultaneous infiltration of mononuclear cells in the adventitia. Later, mononuclear cells infiltrate the adventitia and the blood vessel walls. Thickening of the venous wall begins in the first week. At 16 weeks, the thickness of the venous wall has increased by 18 times, significantly reducing the lumen of the vein. It is assumed that mechanical stress has a decisive role in the increased gene expression of adhesion molecules, growth factors, cytokines and matrix proteins that trigger the inflammation process, together with the emergence and subsequent proliferation of neointimal atheromatosis lesions. It is believed that mechanical pressure on the vein wall is a strong impetus for the transformation and proliferation of smooth muscle cells, leading to reduced flow and termination of AVF function [64].

\section{New Strategies in the Treatment of Vascular Access Dysfunction}

Endovascular interventional techniques (table 2) [6569] proved to be successful in treating stenotic lesions within the access using PTA to treat focal stenoses and coil embolization and ligation to eliminate competing branch veins [69-76]. Nassar et al. [75] used balloon angioplasty of focal stenoses and coil embolization of accessory veins to salvage $83 \%$ of nonmaturing fistulas but concluded that $16.8 \%$ of the fistulas were unsalvageable due to complete occlusion of the outflow tract or the venous outflow tract being prohibitively deep, tortuous, or strictured. Turmel-Rodrigues et al. [77] recently facilitated maturation in $96 \%$ of patients with failing BresciaCimino fistulas, who underwent long-segment arterial angioplasty of the radial artery to $4 \mathrm{~mm}$ in diameter to support the flow rates necessary to promote maturation.

In order to prevent consecutive hemodynamic changes manifesting as decreased blood flow through the AVF, increased venous pressure and prolonged bleeding after $\mathrm{HD}$, early identification of neointimal hyperplasia is very important. There are specific limiting factors, which affect treatment, such as the inability to achieve effective local concentrations of specific antiproliferative agents without causing systemic toxicity. It is believed that radiation can inhibit smooth muscle cell proliferation of endothelial cells and macrophages as a result of DNA damage. 
Table 2. Treatment of stenosed HD AVFs

\begin{tabular}{ll}
\hline Current procedures & Other treatment options (future/experimental) \\
\hline Percutaneous transluminal angioplasty & Radiation therapy \\
\hline Endovascular stent therapy & Infrared therapy \\
\hline Surgical intervention & Drug-eluting perivascular wraps \\
\hline Fish oil & Endothelial cell-loaded gel foam wraps \\
\hline Angiotensin-converting enzyme inhibitors & Vascular endothelial growth factor gene therapy \\
\hline Anticoagulation therapy & \begin{tabular}{l} 
Recombinant elastase PRT-201 \\
\hline Antiplatelet therapy
\end{tabular} \\
$\begin{array}{l}\text { Adventa }{ }^{\circledR} \text { catheter (endovascular balloon catheter with a sheathed microneedle, } \\
\text { used to deliver the drug, and other agents) } \\
\text { Perivascular polymers } \\
\text { Circulating vascular progenitor cells } \\
\text { Photodynamic therapy } \\
\text { Cryoplasty }\end{array}$ \\
\hline
\end{tabular}

Newly formed blood vessels are particularly sensitive to the effects of radiation. Intracoronary gamma radiation of restenosis showed positive findings in $42 \%$ of cases. Similar results were obtained after application of beta radiation. Inhibition of intimal endothelial hyperplasia by gene transfer was achieved in an experimental model involving induction of nitric oxide synthase, inhibitors of cyclindependent kinases and retinoblastoma protein. The use of such therapy in human medicine is still in its infancy. Stents coated with an antiproliferative agent represent the most significant advance in the treatment of venous neointimal hyperplasia. The results of a European multicenter study indicate almost complete absence of stenosis in patients with coronary angioplasty using sacrolimustreated stents, but whether or not the use of such stents will be an effective method in the regulation of vascular access dysfunction is not yet known [78].

Protocols and procedures of therapeutic strategy consist of suppression of conditions that might lead to proliferation of smooth muscle cells, which is highly important for patients with cardiovascular disease. Methotrexate, paclitaxel [79] and sirolimus [80] can have a significant effect on the development of venous neointimal proliferation. The results of some studies indicate that hypercholesterolemia and hyperglycemia increase the risk of emergence of intimal hyperplasia. There are initial positive results concerning the application of infrared radiation for inhibition of intimal hyperplasia [81].

\section{Conclusions}

A functional AVF is a major determinant of successful HD; however, AVFs may be a risk factor for hospitalization in dialysis patients. Knowledge about the potential complications of AVFs should contribute to their timely detection and allow measures to be taken that might prevent deleterious consequences that range from loss of vascular access to serious morbidity, and may ultimately be fatal. Therefore, AVF care should be a priority not only for patients but also for the entire professional team involved in the treatment of dialysis patients.

\section{Acknowledgements}

This work was supported by the Ministry of Education and Science of Serbia, Grants III41010, and by the Medical Faculty of Pristina/K.Mitrovica, Serbia, junior project number 07/09.

References
-1 Quinton WE, Dillard DH, Scribner BH: Cannulation of blood vessels for prolonged hemodialysis. Trans Am Soc Artif Intern Organs 1960;6:104-113.

-2 Konner K: History of vascular access for haemodialysis. Nephrol Dial Transplant 2005; 20:2629-2635.

3 Allon M: Current management of vascular access. Clin J Am Soc Nephrol 2007;2:786-800. 
-4 Schon D, Blume WS, Niebauer K, Hollenbeak CS, de Lissovoy G: Increasing the use of arteriovenous fistula in hemodialysis: economic benefits and economic barriers. Clin J Am Soc Nephrol 2007;2:268-276.

5 Metcalfe W, Khan IH, Prescott GJ, Simpson K, Macleod AM, on behalf of the Scottish Renal Registry: hospitalization in the first year of renal replacement therapy for end-stage renal disease. QJM 2003;96:899-909.

-6 Ortega T, Ortega F, Diaz-Corte C, Rebollo P, Ma Baltar J, Alvarez-Grande J: The timely construction of arteriovenous fistulae: a key to reducing morbidity and mortality and to improving cost management. Nephrol Dial Transplant 2005;20:598-603.

7 Manns B, Tonelli M, Yilmaz S, Lee H, Laupland K, Klarenbach S, Radkevich V, Murphy B: Establishment and maintenance of vascular access in incident hemodialysis patients: a prospective cost analysis. J Am Soc Nephrol 2005; 16:201-209.

8 Scribner BH. Medical dilemmas: the old is new. Nat Med 2002;8:1066-1067.

-9 Allon M, Robbin M: Increasing arteriovenous fistulas in hemodialysis patients: problems and solutions. Kidney Int 2002;62: 1109-1124.

-10 Ethier J, Mendelssohn DC, Elder SJ, Hasegawa T, Akizawa T, Akiba T, Canaud BJ, Pisoni RL: Vascular access use and outcomes: an international perspective from the dialysis outcomes and practice patterns study. Nephrol Dial Transplant 2008;23: 3219-3226.

-11 Tordoir J, Canaud B, Haage P, Konner K, Basci A, Fouque D, Kooman J, Martin-Malo A, Pedrini L, Pizzarelli F, et al: EBPG on vascular access. Nephrol Dial Transplant 2007; 22(suppl 2):ii88-ii117.

12 Van Tricht I, De Wachter D, Tordoir J, Verdonck P: Hemodynamics and complications encountered with arteriovenous fistulas and grafts as vascular access for hemodialysis: a review. Ann Biomed Eng 2005;9:1142-1157.

13 Luxton G: The CARI guidelines. Timing of referral of chronic kidney disease patients to nephrology services (adult). Nephrology (Carlton) 2010;15(suppl 1):S2-S11.

-14 K/DOQI Workgroup Clinical practice guidelines for vascular access. Am J Kidney Dis 2006;48(suppl 1) :S176-S247.

15 Besarab A, Brouwer D: Improving arteriovenous fistula construction: fistula first initiative. Hemodial Int 2004;8:199-206.

16 http://www.kidney.org/professionals/kdoqi/guideline_uphd_pd_va/va_guide1.htm.

-17 Saxena AK, Panhotra BR, Al-Mulhim AS: Vascular access related infections in hemodialysis patients. Saudi J Kidney Dis Transpl 2005; 16:46-51.

18 Stolic R: Infection of arteriovenous graft for hemodialysis. Praxis Medica 2007;35:113115 .
19 Schild AF, Perez E, Gillaspie E, Seaver C, Livingstone J, Thibonnier A: Arteriovenous fistulae vs arteriovenous grafts: a retrospective review of 1700 consecutive vascular access cases. J Vasc Access 2008;9:231-235.

20 Saeed F, Kousar N, Sinnakirouchenan R, Ramalingam VS, Johnson PB, Holley JL: Blood loss through AV fistula: a case report and literature review. Int J Nephrol. 2011;2011: 350870.

21 Wiese P, Nonnast-Daniel B: Colour Doppler ultrasound in dialysis access. Nephrol Dial Transplant 2004;19:1956-1963.

22 Morris ST, McMurray JJ, Rodger RS, Jardine AG: Impaired endothelium-dependent vasodilatation in uraemia. Nephrol Dial Transplant 2000;15:1194-1200.

23 Kooman JP, Wijnen JA, Draaijer P, van Bortel LM, Gladziwa U, Peltenburg HG, Struyker-Boudier HA, van Hooff JP, Leunissen KM: Compliance and reactivity of the peripheral venous system in chronic intermittent hemodialysis. Kidney Int 1992;41:10411048

24 Wali MA, Eid RA, Al-Homrany MA: Smooth muscle changes in the cephalic vein of renal failure patients before use as an AVF. J Smooth Muscle Res 2002;38:75-85.

25 Turmel-Rodrigues L, Pengloan J, Blanchier D, Abaza M, Birmelé B, Haillot O, Blanchard D: Insufficient dialysis shunts: improved long-term patency rates with close hemodynamic monitoring, repeated PTA and stent placement. Radiology 1993;187:273-278.

26 Kanterman RY, Vesely TM, Pilgram TF, Guy BW, Windus DW, Picus D: Dialysis access grafts: anatomic location of venous stenoses and results of angioplasty. Radiology 1995; 195:135-139.

-27 Trerotola SO, Stavropoulos SW, ShlanskyGoldberg R, Tuite CM, Kobrin S, Rudnick MR: Hemodialysis-related venous stenosis: treatment with ultra-high pressure angioplasty balloons. Radiology 2004;231:259262.

28 Ozmen N, Cebeci BS, Kardesoglu E, Atasoyu EM, Unver S, Celik T, Aparci M, Dincturk M: Relationship between P-wave dispersion and effective hemodialysis in chronic hemodialysis patients. Med Princ Pract 2007;16:147150.

-29 Basile C, Lomonte C, Vernaglione L, Casucci F, Antonelli M, Losurdo N: The relationship between the flow of arteriovenous fistula and cardiac output in haemodialysis patients. Nephrol Dial Transplant 2008;23: 282-287.

30 London GM: Left ventricular alterations and end-stage renal disease. Nephrol Dial Transplant 2002;17:29-36.

-31 Ayus JC, Mizani MR, Achinger SG, Thadhani R, Go AS, Lee SH: Effects of short daily versus conventional hemodialysis on left ventricular hypertrophy and inflammatory markers: a prospective, controlled study. J Am Soc Nephrol 2005;16:2778-2788.
32 Román-García P, Rodríguez-García M, Cabezas-Rodríguez I, López-Ongil S, DíazLópez B, Cannata-Andía JB: Vascular calcification in patients with chronic kidney disease: types, clinical impact and pathogenesis. Med Princ Pract 2011;20:203-212.

33 Hiremath S, Doucette SP, Richardson R, Chan K, Burns K, Zimmerman D: Left ventricular growth after 1 year of haemodialysis does not correlate with arteriovenous access flow: a prospective cohort study. Nephrol Dial Transplant 2010;25:2656-2661.

34 Gallardo RM, Morong FV, Pino GG, Arias IC, Gallego RH, Magariños FG: Congestive heart failure in patients with advanced chronic kidney disease: association with preemptive vascular access placement. Nefrologia 2012;32:206-212.

- 35 Foley RN, Curtis BM, Randell EW, Parfrey PS: Left ventricular hypertrophy in new hemodialysis patients without symptomatic cardiac disease. Clin J Am Soc Nephrol 2010; 5:805-813.

-36 Iwashima Y, Horio T, Takami Y, Inenaga T, Nishikimi T, Takishita S, Kawano Y: Effects of the creation of arteriovenous fistula for hemodialysis on cardiac function and natriuretic peptide levels in CRF. Am J Kidney Dis 2002;40:974-982.

37 Scheltinga MR, van Hoek F, Bruijninckx CM: Time of onset in haemodialysis accessinduced distal ischaemia (HAIDI) is related to the access type. Nephrol Dial Transplant 2009;24:3198-3204

- 38 Lazarides MK, Staramos DN, Kopadis G Maltezos C, Tzilalis VD, Georgiadis GS: Onset of arterial 'steal' following proximal angioaccess: immediate and delayed types. Nephrol Dial Transplant 2003; 18:23872390.

39 Schanzer A, Nguyen LL, Owens CD, Schanzer $\mathrm{H}$ : Use of digital pressure measurements for the diagnosis of AV access-induced hand ischemia. Vasc Med 2006;11:227-231.

40 Leon C, Asif A: Arteriovenous access and hand pain: the distal hypoperfusion ischemic syndrome. Clin J Am Soc Nephrol 2007;2:175-183.

41 Bachleda P, Utikal P, Kojecky Z, Drac P, Köcher M, Cerna M, Zadrazil J: Autogenous arteriovenous elbow fistula for haemodialysis and upper extremity ischemia. Biomed Pap Med Fac Univ Palacky Olomouc Czech Repub 2007;151:129-132.

42 Namdari S, Park MJ, Weiss AP, Carney WI Chronic hand ischemia treated with radial artery balloon angioplasty: case report. J Hand Surg Am 2008;33:551-554.

43 Tordoir JH, Dammers R, van der Sande FM: Upper extremity ischemia and hemodialysis vascular access. Eur J Vasc Endovasc Surg 2004:27:1-5

44 Mickley V: Steal syndrome - strategies to preserve vascular access and extremity. Nephrol Dial Transplant 2008;23:19-24. 
-45 Regalado S, Navuluri R, Vikingstad E: Distal revascularization and interval ligation: a primer for the vascular and interventional radiologist. Semin Intervent Radiol 2009;26: 125-129.

-46 Rogers NM, Lawton PD: Ischaemic monomelic neuropathy in a non-diabetic patient following creation of an upper limb arteriovenous fistula. Nephrol Dial Transplant 2006;22:933-935.

47 Andary MT, Mahal BS: Ischemic monomelic neuropathy, http://emedicine.medscape. com/article/315915-overview (updated Jan 19, 2010).

48 Stolic R, Krstic N, Belic B, Stolic D, Zivic Z: Fibrinolytic parameters for haemodialysis in patients with arteriovenous fistulae dysfunction. Serbian J Exp Clin Res 2009; 10: 49-52.

-49 Stolic R, Trajkovic G, Peric V, Jovanovic A, Markovic S, Sovtic S, Subaric-Gorgieva G: The influence of atherosclerosis and plasma $\mathrm{D}$-dimer concentration in patients with a functioning arteriovenous fistula for maintenance hemodialysis. Int Urol Nephrol 2008;40:503-508.

50 Stolic R: Functionality Artificial Arteriovenous Fistula for Hemodialysis and Adequacy of Hemodialysis; thesis, Kosovska Mitrovica, 2006.

-51 Dember LM, Beck GJ, Allon M, Delmez JA, Dixon BS, Greenberg A, Himmelfarb J, Vazquez MA, Gassman JJ, Greene T, et al for the Dialysis Access Consortium Study Group: Effect of clopidogrel on early failure of arteriovenous fistulas for hemodialysis. A randomized controlled trial. JAMA 2008; 299:2164-2171.

52 Stolic R, Mitrovic S, Stolic D, Mitic N: Early pathohistological changes in dysfunction of arteriovenous fistula for hemodialysis (in Serbian). Vojnosanit Pregl 2010;67:65-68.

53 Bonatti J, Oberhuber A, Schachner T, Zou Y, Hammerer-Lercher A, Mittermair R, Laufer G: Neointimal hyperplasia in coronary vein grafts: pathophysiology and prevention of a significant clinical problem. Heart Surg Forum 2004;7:72-77.

-54 Agarwal A, Segal MS: Intimal exuberance: vein in jeopardy. Am J Pathol 2003;162:17591761.

55 Cummins PM, von Offenberg SN, Killeen MT, Birney YA, Redmond EM, Cahill PA: Cyclic strain-mediated matrix metalloproteinase regulation within the vascular endothelium: a force to be reckoned with. Am J Physiol Heart Circ Physiol 2007;292:28-42.

56 Widlansky M, Gokce N, Keaney J, Vita J: The clinical implications of endothelial function. J Am Coll Cardiol 2003;42:1149-1160.

-57 Zou Y, Dietrich H, Hu Y, Mettler B, Wick G, Yu Q: Mouse model of venous bypass graft arteriosclerosis. Am J Pathol 1998;153:13011310.
58 Kokubo T, Kchida H, Choi ET: Integrin $\alpha_{v} \beta_{3}$ as a target in the prevention of neointimal hypeplasia. J Vasc Surg 2007;45:33-38.

59 Nath KA, Kanakiriya SK, Grande JP, Croatt AJ, Katusic ZS: Increased venous proinflamatory gene expression and intimal hyperplasia in an aorto-caval fistula model in the rat. Am J Pathol 2003;162:2079-2090.

60 Chamberlain J, Evans D, King A, Dewberry R, Dower S, Crossman D, Francis S: Interleukin-1 $\beta$ and signaling of interleukin-1 in vascular wall and circulating cells modulates the extent of neointima formation in mice. Am J Pathol 2006;168:1396-1403.

61 McGregor E, Gosling M, Beattie DK, Ribbons DMP, Davies AH, Powell JT: Circumferential stretching of saphenous vein smooth muscle enhances vasoconstrictor responses by Rho kinase-dependent pathways. Cardiovasc Res 2002;53:219-226.

- 62 Hofstra L, Tordoir JH, Kitslaar PJ, Hoeks AP, Daemen MJ: Enhanced cellular proliferation in intact stenotic lesions derived from lumen arteriovenous fistulae and peripheral bypass grafts. Circulation 1996;94:1283-1290.

63 Roy-Chaudhury P: Endothelial progenitor cells, neointimal hyperplasia, and hemodialysis vascular access dysfunction. Circulation 2005;112:3-5.

64 Huang Y, Salu K, Liu X, Li S, Wang L, Verbeken E, Bosmans J, De Scheerder I: Methotrexate loaded SAE coated coronary stents reduce neointimal hyperplasia in a porcine coronary model. Heart 2004;90:195-199.

65 Roy-Chaudhury P, Melhem M, Husted T, Kelly BS: Solutions for hemodialysis vascular access dysfunction: thinking out of the box!! J Vasc Access 2005;6:3-8.

66 Roy-Chaudhury P, Sukhatme VP, Cheung AK: Hemodialysis vascular access dysfunction: a cellular and molecular viewpoint. J Am Soc Nephrol 2006;17:1112-1127.

67 Lee T, Roy-Chaudhury P: Advances and new frontiers in the pathophysiology of venous neointimal hyperplasia and dialysis access stenosis. Adv Chronic Kidney Dis 2009;16: 329-338.

68 Lee T: Hemodialysis vascular access dysfunction; in Carpi A, Donaldio C, Tramonti G (eds): Progress in Hemodialysis - From Emergent Biotechnology to Clinical Practice. Rijeka, InTech, 2011, pp 365-388.

69 Schild AF: Maintaining vascular access: the management of hemodialysis arteriovenous grafts. J Vasc Access 2010;11:92-99.

70 Byung Ha Lee, Nam HY, Kwon T, Kim SJ, Kwon GY, Jeon HJ, Lim HJ, Lee WK, Park J, Ko YJ, Kim DJ: Paclitaxel-coated expanded polytetrafluoroethylene haemodialysis grafts inhibit neointimal hyperplasia in porcine model of graft stenosis. Nephrol Dial Transplant 2006;21:2432-2438.
Clark TW, Cohen RA, Kwak A, Markmann JF, Stavropoulos SW, Patel AA, Soulen MC, Mondschein JI, Kobrin S, Shlansky-Goldberg RD, Trerotola SO: Salvage of nonmaturing native fistulas by using angioplasty. Radiology 2007;242:286-292.

72 Beathard GA, Arnold P, Jackson J, Litchfield T: Physician Operators Forum of RMS Lifeline. Aggressive treatment of early fistula failure. Kidney Int 2003;64:1487-1494.

73 Shin SW, Do YS, Choo SW, Lieu WC, Choo IW: Salvage of immature arteriovenous fistulas with percutaneous transluminal angioplasty. Cardiovasc Intervent Radiol 2005;28: 434-438.

74 Turmel-Rodrigues L, Mouton A, Birmelé B, Billaux L, Ammar N, Grézard O, Hauss S, Pengloan J: Salvage of immature forearm fistulas for haemodialysis by interventional radiology. Nephrol Dial Transplant 2001;16: 2365-2371.

75 Nassar GM, Nguyen B, Rhee E, Achkar K: Endovascular treatment of the "failing to mature' arteriovenous fistula. Clin J Am Soc Nephrol 2006;1:275-280.

76 Faiyaz R, Abreo K, Zaman F, Pervez A, Zibari G, Work J: Salvage of poorly developed arteriovenous fistulae with percutaneous ligation of accessory veins. Am J Kidney Dis 2002;39:824-827.

77 Turmel-Rodrigues L, Boutin JM, Camiade C, Brillet G, Fodil-Chérif M, Mouton A: Percutaneous dilation of the radial artery in nonmaturing autogenous radial-cephalic fistulas for hemodialysis. Nephrol Dial Transplant 2009;24:3782-3788.

78 Rotmans JI, Pattynama PM, Verhagen HJ, Hino I, Velema E, Pasterkamp G, Stroes ES: Sirolimus-eluting stents to abolish intimal hyperplasia and improve flow in porcine arteriovenous grafts: a 4-week followup study. Circulation 2005;111:153715153742 .

79 Absood A, Furutani A, Kawamura T, Graham LM: A comparison of oxidized LDL-induced collagen secretion by graft and aortic SMCs: role of PDGF. Am J Physiol Heart Circ Physiol 2004;287:1200-1206.

80 Lin CC, Chang CF, Lai MY, Chen TW, Lee PC, Yang WC: Far-Infrared therapy: a novel treatment to improve access blood flow and unassisted patency of arteriovenous fistula in hemodialysis patients. J Am Soc Nephrol 2007; 18:985-992.

-81 Akita GY, Date T, Treleaven C, Vincent KA, Woodcock D, Cheng SH, Gregory RJ, Jiang $\mathrm{C}$ : Adenovirus-mediated expression of $\beta$ adrenergic receptor kinase C-terminus reduces intimal hyperplasia and luminal stenosis of arteriovenous polytetrafluoroethylene grafts in pigs. Circulation 2005; 111 : 1679-1684. 